\title{
MICROCRÉDITO E EMPREENDEDORISMO: UMA ANÁLISE DA SITUAÇÃO DOS BENEFICIÁRIOS DO MICROCRÉDITO DA CIDADE DE XAI-XAI, GAZA E MOÇAMBIQUE
}

\author{
Nelson Maria Rosario ${ }^{1}$ \\ Mutemba France Daniel ${ }^{2}$ \\ Aurélio Ernesto Muchanga ${ }^{3}$
}

\section{Resumo}

O presente artigo analisa a importância que as instituições de microcrédito têm no fomento de atividades empreendedoras da cidade de Xai-Xai, província de Gaza. Para o alcance do objetivo preconizado o estudo teve uma abordagem qualitativa e quantitativa, sendo a entrevista e inquéritos as técnicas usadas para a recolha dos dados. Foram inqueridos catorze beneficiários do microcrédito, sendo o Fundo de desenvolvimento da Mulher (FDM) e a Sociedade de Créditos de Moçambique (SOCREMO) as instituições fornecedoras do microcrédito, ambos sediados na cidade de Xai-Xai. A pesquisa constatou que a procura de acesso a microcrédito deve-se principalmente a falta de emprego e a busca de fonte de rendimento. Os resultados da pesquisa mostraram que muitos dos beneficiários investiram ou apostaram em pequenos negócios como (abertura de lojas de venda de produtos alimentares, de higiene, roupa, calçados, bares, entre outros) para minimizar a situação do desemprego e geração de renda.

Palavras-chaves: Microcrédito. Empreendedorismo. Xai-Xai.

\section{MICROCREDIT AND ENTREPRENEURSHIP: AN ANALYSIS OF THE SITUATION OF THE MICROCREDIT BENEFICIARIES OF THE CITY OF XAI-XAI, GAZA, MOZAMBIQUE}

\begin{abstract}
This paper analyses the role of microcredit institutions in fostering entrepreneurship activities in the City of Xai-Xai, Province of Gaza in Mozambique. To reach the conclusion, the study opted for a qualitative and quantitate approach, whereby interviews were carried out, as tools to for data gathering. Fourteen credit beneficiaries from Fund for Women Development [FDM] and Credit Society of Mozambique [SOCREMO] were interviewed, both are headquartered in Maputo, however with branches in the City of Xai-Xai. The study revealed that the demand for credit was fostered owing to mainly unemployment, and a quest for means of income. The results therefore, showed that most beneficiaries invested or opted in small business as: new shops to sell groceries, cleaning products, clothes, shoes, bars, and many others, etc., as means to minimize the unemployment situation and generation of income.
\end{abstract}

Key-Words: Microcredit. Entrepreneurship. Xai-Xai

\footnotetext{
1 Mestrado em Geografia pela Universidade Federal do Rio Grande do Norte (2014) e Doutorado em Desenvolvimento Rural pela Universidade Federal do Rio Grande do Sul (2020). Email: nemaro17@ gmail.com.

${ }^{3}$ Graduação em Turismo pela Universidade Eduardo Modlane (2007). Email: aurobaito@ yahoo.com.br
} 
Microcrédito e empreendedorismo: uma análise da situação dos beneficiários do microcrédito da cidade de Xai-Xai, Gaza e Moçambique

\section{MICROCRÉDITO Y EMPRENDIMIENTO: UN ANÁLISIS DE LA SITUACIÓN DE LOS BENEFICIARIOS DE MICROCRÉDITO DE LA CIUDAD DE XAI-XAI, GAZA, MOZAMBIQUE}

\section{Resumen}

Este artículo analiza la importancia que tienen las instituciones de microcrédito para fomentar las actividades empresariales en la ciudad de Xai-Xai, provincia de Gaza. Para lograr el objetivo recomendado, el estudio tuvo un enfoque cualitativo y cuantitativo, siendo la entrevista y las encuestas las técnicas utilizadas para la recopilación de datos. Se encuestó a catorce beneficiarios de microcréditos, siendo el Fondo de Desarrollo de la Mujer (FDM) y la Sociedad de Créditos de Mozambique (SOCREMO) las instituciones proveedoras de microcrédito, ambas con sede en la ciudad de Xai-Xai. La encuesta encontró que la demanda de acceso al microcrédito se debe principalmente a la falta de empleos y la búsqueda de una fuente de ingresos. Los resultados de la encuesta mostraron que muchos de los beneficiarios invirtieron o invirtieron en pequeñas empresas (abriendo tiendas que venden alimentos, higiene, ropa, zapatos, bares, etc.) para minimizar la situación de desempleo y generación de ingresos.

Palabras clave: Microcrédito. Emprendimiento. Xai-Xai.

\section{INTRODUÇÃO}

O presente artigo tem como objetivo analisar a importância que as instituições de microcrédito têm no fomento de atividades empreendedoras na cidade de Xai-Xai-GazaMoçambique.

O microcrédito pode ser definido como um empréstimo de pequeno valor, dado a empreendedores de baixo rendimento. É uma das formas de potencializar o desenvolvimento de pequenos negócios, através de crédito para indivíduos que, pelo baixo nível de formalização de seus negócios, ou pela inexistência de garantias, não conseguem acessar crédito junto às instituições tradicionais do sistema financeiro. Ou seja, além de pequeno valor, o crédito é direcionado especificamente para a camada da população de baixa renda, em geral excluída do sistema financeiro convencional, e em especial os micro empreendedores do segmento informal da economia (MARTINS et al, 2002; PARENTE, 2002).

Nesse âmbito o microcrédito como uma componente de micro finanças, tem por objetivo apresentar soluções socioeconômicas para a camada da população mais desfavorecida, geralmente excluída no leque dos bancos que segundo Santos (2008) os bancos são instituições supremas do circuito superior da economia urbana.

Milton Santos (2008), em sua análise do 'espaço dividido' nos países subdesenvolvidos, aponta para a existência, nas cidades desses países, de dois circuitos 
econômicos. A configuração dos circuitos tem origem nos processos de industrialização e de modernização vivenciados nesses países, guiados por firmas multinacionais intensivas em tecnologia e geradoras de um número limitado de empregos.

A realidade urbana dos países de Terceiro Mundo divide-se em circuito superior e circuito inferior da economia. Segundo Santos (2008) o circuito superior está ligado aos benefícios do progresso tecnológico e a parte da população que pode usufruir os mesmos, enquanto no circuito inferior estão aqueles que não podem pagar por tais benefícios. $O$ circuito superior é formado pela indústria urbana, bancos, serviços, transportadoras e indústria de exportação. Por sua vez, o circuito inferior relaciona-se a atividades de menor porte e pouca modernização, como comércio de varejo, serviços não modernos e fabricação que não possuem capital intensivo.

O público alvo do microcrédito é, predominantemente, composto por donos de empresas que realizam uma atividade económica autónoma, muitas vezes, informal e geralmente, auto- financiada através de poupanças próprias ou de parentes e amigos (o que foi relatado é a essência do circuito inferior da economia urbana, são pessoas que conhecem bem o seu ramo de atividade e cuja orientação é voltada primordialmente para o sustento de sua família, sem grandes expectativas de crescimento. Por isso, a maior parte da demanda por microcrédito destina-se a capital de giro para cobrir dificuldades momentâneas de liquidez ou utilizar chances de eventuais negócios favoráveis (NITSCH; SANTOS, 2001).

Para Santos (2008), no circuito inferior o crédito obtido pela população pobre tem caráter pessoal e está ligado ao consumo básico. O circuito inferior tem como base a força de trabalho, é composto por uma população de baixa ou nula qualificação profissional e desprovida de capital, onde as atividades praticadas estão ligadas diretamente a sobrevivência e as questões cotidianas da população, sobretudo ao consumo de bens e serviços básicos.

$\mathrm{O}$ presente trabalho adotou uma abordagem quantitativa e qualitativa descritiva, empregando-se o estudo de caso. Do ponto de vista dos procedimentos técnicos, foram selecionados a pesquisa bibliografia e documental. No que concerne as técnicas de recolha de dados recorreu-se a entrevistas com os dirigentes das instituições de microcrédito da cidade de Xai-Xai, de forma a recolher dados internos da organização e quantificar pessoas que já beneficiaram do microcrédito. Ainda foram aplicados inquéritos ou questionários aos beneficiários do microcrédito com a intenção de perceber qual o impacto que a obtenção do microcrédito teve na vida quotidiana dos beneficiários. 
Microcrédito e empreendedorismo: uma análise da situação dos beneficiários do microcrédito da cidade de Xai-Xai, Gaza e Moçambique

Foi tomada como população nesta pesquisa os beneficiários do microcrédito fornecidos por duas instituições de microcrédito situadas na cidade de Xai-Xai, nomeadamente a Sociedade de Créditos de Moçambique (SOCREMO) e o Fundo de Desenvolvimento da Mulher (FDM). Para a seleção dos beneficiários do microcrédito foram utilizadas técnicas de amostragens probabilísticas, especificamente a aleatória simples e estratificada. Assim sendo, foram inqueridos catorze (14) beneficiários do microcrédito obtidos nas instituições SOCREMO e FDM.

\section{BREVE HISTORIAL SOBRE O SURGIMENTO DO MICROCRÉDITO}

A primeira experiência com o microcrédito deu-se em 1846 no Sul da Alemanha, numa época de inverno rigoroso, em que os fazendeiros da região se endividaram com empréstimos vindos dos agiotas ${ }^{4}$. Foi quando o pastor Raiffensem criou a Associação do pão e cedeu farinha de trigo para os fazendeiros fabricarem e comercializarem pão, e com o lucro pagarem as dívidas, (SILVA, 2001 apud PRADO, 2002, p.9).

A primeira instituição de microcrédito nasceu em 1980, com o Grameen Bank, de Bangladesh, tendo Muhammad Yunus como fundador e diretor gerente, o qual começou a notar que os vizinhos próximos à universidade em que lecionava, viviam na miséria e desenvolviam algum tipo de atividade produtiva, mas estavam reféns de agiotas, que levavam a maior parte dos lucros. Vendo tal situação, Yunus começou a emprestar pequenas quantias de dinheiro sem cobrar juros a um pequeno grupo familiar. Tal atitude levou a consciência de se criar uma instituição que atendesse a população mais necessitada (Fernandes, 2008, p.27).

Segundo as palavras de Yunus, foi então que tudo começou,

Eu não tinha absolutamente intenção de me converter em credor; queria apenas resolver um problema imediato. Até hoje considero que meu trabalho e o de meus colegas do Grammen têm um único objetivo: por fim á pobreza, esse flagelo que humilha e denigre tudo o que um ser humano representa (YUNUS, 2000 apud PRADO, 2002, p.99).

Inicialmente o Dr. Yunus fazia as suas operações com famílias produtoras rurais focalizando as mulheres, utilizando o sistema de garantias morais mútuas formando grupos de cinco pessoas que ficavam responsáveis umas das outras. Os grupos assumiam a

4 Agiota é a pessoa que faz prática da usura, ou seja, empresta dinheiro a outra no mercado informal, sem a devida autorização legal para isso. 
responsabilidade de devedores no reembolso de qualquer empréstimo relacionado a qualquer sócio do grupo e utilizavam as informações para minimizar os custos. Com a iniciativa de emprestar pequenas somas em dinheiro às pessoas carenciadas de uma pequena comunidade pobre bengalesa, no intuito, de ajudar as populações a resolverem os seus problemas de sobrevivência quotidiana, nasciam assim as primeiras práticas de microcrédito.

Após sentir que aquelas pessoas pobres eram merecedoras de crédito e que pagavam os seus empréstimos destinados as suas atividades produtivas aumentaram-se o montante do empréstimo. Mais tarde, em 1978 o Dr. Yunus conseguiu financiamento e doações junto aos bancos privados e internacionais para criar o Banco Grameen. Assim, surgiu a primeira instituição financeira do microcrédito do mundo (YUNUS e JOLIS, 2000, p.117).

Segundo David Gibbons (1999), "Grameen" significa Aldeia em Bengali, por isso, o Banco Grameen significa Banco da Aldeia, porque quase todas as suas transações eram realizadas nas aldeias dos clientes em encontro semanais. O Banco Grameen, fundado por Yunus e também conhecido como Banco dos Pobres, dando crédito às pessoas carenciadas pertencentes a uma zona do Bangladesh.

O Banco Grameen tinha inicialmente como objetivos: (i) Alargar os serviços bancários a homens e mulheres pobres; (ii) Eliminar a exploração dos pobres pelos usuários; (iii) Criar oportunidade de autoemprego para os vastos recursos humanos nacionais não utilizados e subutilizados; (iiii) Envolver as populações desfavorecidas em estruturas organizacionais que possam encontrar força sóciopolítica e econômica, através do apoio mútuo; e (iiiii) Tornar o velho ciclo vicioso baixo rendimento, baixa poupança, baixo investimento num sistema mais dinâmico de baixo rendimento, crédito, investimento, maior rendimento, mais crédito, mais investimento, maior rendimento (David Gibbons, 1999, p.10).

A experiência do Banco Grameen foi replicada em dezenas de países, respeitando as condições sociais, culturais e econômicas de cada país. Isto devido a sua performance no combate a pobreza. Como prova disto, o Dr. Yunus foi distinguido com o prémio Nobel da Paz em 2006 pelo Comité do Parlamento da Noruega em Oslo ${ }^{5}$.

\section{Diferentes Noções sobre o Conceito de Microcrédito}

Geralmente muita bibliografia especializada quando trata da temática microcrédito alude a experiências de concessão de pequenos financiamentos reembolsáveis, com base em

\footnotetext{
${ }^{5}$ http ://pt.wikipedia.org/wiki/Muhammad_Yunus
} 
Microcrédito e empreendedorismo: uma análise da situação dos beneficiários do microcrédito da cidade de Xai-Xai, Gaza e Moçambique

juros positivos, destinados a pessoas pobres que sobrevivem, precariamente, no setor informal que, portanto, é apenas uma dimensão do circuito inferior da economia.

Microcrédito é a concessão de empréstimos de baixo valor a pequenos empreendedores informais e microempresas sem acesso ao sistema financeiro tradicional, principalmente por não terem como oferecer garantias reais. É um crédito destinado à produção (capital de giro e investimento) e é concedido com o uso de metodologia específica (Barone 2002, p. 14).

Alves e Soares (2004) definem microcrédito como aquela que, no contexto das micro finanças, dedica-se a conceder crédito para o financiamento de pequenos empreendimentos e diferencia-se dos demais tipos de empréstimo essencialmente pela metodologia utilizada, bastante diferente daquela adotada para as operações de crédito tradicionais.

Já Barone et al. (2002) definem o microcrédito como a concessão de empréstimos de baixo valor a pequenos empreendedores informais e microempresas sem acesso formal ao sistema financeiro tradicional, principalmente por não terem como oferecer garantias reais, ou seja, trata-se de um crédito destinado à produção (capital de giro e investimento) e concedido com o uso de metodologia específica.

Para Lhacher (2003) a ideia de microcrédito direciona-se a microempreendedores que atuam de maneira formal ou informal, cujo acesso ao sistema financeiro tradicional (circuito superior) é penoso para essas pessoas que buscam montar ou ampliar seu negócio. Assim sendo, fica claro que se trata de um instrumento direcionado a inclusão social de uma camada da população que se encontra à margem da sociedade que tem alguma atividade produtiva e que precisa de financiamento para o desenvolvimento do seu negócio.

O microcrédito apresenta algumas características que o diferencia da forma tradicional de concessão de créditos. Segundo ainda Lhacher (2003), essas características são: i) públicoalvo; ii) finalidade; e iii) montante. Nesta direção, o público-alvo são aquelas pessoas que são consideradas pobres, cuja finalidade seja montar ou ampliar seu negócio a fim alavancar as suas atividades iniciais, com uma quantidade de recursos pequena.

Segundo Costanzi (2002), o microcrédito pode ser entendido como crédito para pobres ou microempreendedores de baixa renda sem acesso ao crédito formal. Dado sem garantias reais, propicia o mecanismo autossustentável de combate à pobreza e à exclusão social.

O microcrédito é, fundamentalmente, a democratização do crédito. A sua compreensão acerca do microcrédito ressalta a autossustentabilidade em oposição a ações assistencialistas de combate à pobreza que precisam de recursos a fundo perdido para combatê-la, muitas vezes sem impactos 
duradouros ou de longo prazo sobre o público beneficiário (Costanzi 2002,p. $32)$.

No entanto, Parente (2002, p.14) afirma que o microcrédito é apenas um dos serviços financeiros das microfinanças. Além dos pequenos valores, o crédito é direcionado a um público específico, ou seja, à camada da população de mais baixa renda, em geral excluída do sistema financeiro convencional, em especial aos microempreendedores do segmento informal da economia.

Ainda o mesmo autor afirma que o microcrédito possui características voltadas exclusivamente para a população de baixa renda, a exemplo de:

(1)Trabalhar diretamente na comunidade, através de visitas e encontros que esclarecem à comunidade os pré-requisitos necessários para um provável cliente potencial; (2) Fornecimento rápido do empréstimo, visto que ninguém quer esperar meses para ter em mãos o empréstimo; (3) Não há necessidade de grandes garantias; (4) Trabalhar com atividades econômicas já existentes ou que estejam começando e no mercado local; (5) Começar com pequenos investimentos, de modo que prove a capacidade do pequeno empresário de reembolsar e verificar o nível de crescimento devido ao empréstimo; (6) Fornecer empréstimos crescentes, na medida em que os investimentos são bem-sucedidos (Parente 2002, p.14).

Tanto Costanzi (2002) quanto Parente (2002) demarcam a ideia de que o microcrédito não é filantropia, doação ou mesmo simples transferência de renda. Em suma, os autores ora referidos advogam que o microcrédito propicia uma nova relação emancipatória e de confiança, mais permanente e devidamente adequada entre os "tomadores de crédito" e as organizações financeiras, sejam governamentais, do setor privado ou da sociedade civil.

Segundo Silva (2002) aproximadamente 500 milhões de pessoas pobres no mundo demandam por algum tipo de sistema financeiro e as microfinanças atendem apenas uma pequena parte dessa demanda, cerca de 16 milhões de pessoas. As principais instituições de microfinanças são os bancos comerciais, os intermediários não-financeiros, as ONGs e as uniões de crédito. O grande problema é a autosustentabilidade, pois estima-se que apenas $1 \%$ das instituições são autossustentáveis e as demais são dependentes de doações.

Para Alice e Ruppenthal (2012) o microcrédito desempenha o papel de contribuir para que o indivíduo desenvolva seu capital humano, além do capital monetário e associa o microcrédito a uma ferramenta capaz de libertar os indivíduos da condição de pobreza e atingir a dignidade, o respeito e a melhorar a qualidade de vida.

No que diz respeito às funções do microcrédito, há uma ampla área de consenso entre os estudiosos do tema no sentido de que essa política permite a redução da pobreza e da 
Microcrédito e empreendedorismo: uma análise da situação dos beneficiários do microcrédito da cidade de Xai-Xai, Gaza e

Moçambique

exclusão, pois viabiliza a disponibilidade de ativos produtivos para os pobres e excluídos sociais. Segundo Costanzi (2002, p. 22), “da mesma forma que a educação e o capital humano constituem importantes ativos produtivos no combate à pobreza, o acesso ao crédito também se mostra como importante aliado nessa missão".

Fica claro que o microcrédito não deve ser entendido apenas como uma medida de política econômica, mas também como de política social, pois deve oferecer acessibilidade para agentes econômicos que dantes estavam excluídos do mercado financeiro.

\section{MICROCRÉDITO EM MOÇAMBIQUE}

Segundo Laice (2000), originariamente, a atividade microfinanceira em Moçambique foi implementada por ONG's, ao abrigo de acordos bilaterais e multilaterais entre o Governo de Moçambique e seus parceiros internacionais. A maioria dos programas teve como embrião projetos de ajuda à população vulnerável, vítima do conflito armado ou de calamidades naturais em que a concessão de créditos "surgiu para garantir um mínimo de recursos para os beneficiários dos seus programas" (LARCOMBE, 1998, p. 38)

Atualmente a atividade microfinanceira em Moçambique tem estado a ganhar proeminência devido ao reconhecimento da capacidade latente dos pobres em desenvolver atividades empresariais em pequena escala, desde que devidamente encorajado para o efeito. Para além de contribuir para a criação de emprego, incluindo uma maior participação de mulheres pobres e donas de casas na vida econômica ativa, as micro finanças podem contribuir decisivamente para o nascimento de uma nova classe empresarial formal (LAICE, 2000, p.32).

\section{As fases de desenvolvimento das instituições de Microcrédito ou Microfinanças em Moçambique}

Furcane (2007, p.19), citando o manual de formação de gestores de crédito refere-se que o desenvolvimento da atividade microfinanceira em Moçambique pode ser subdivido em 3 fases:

I. Fase que vai desde 1992 até 1997 - caracterizou-se ainda de acordo com este autor pela concentração da atividade microfinanceira nas mãos de ONG`s geridas pelos estrangeiros. Os serviços microfinanceiros eram na sua maioria oferecidos as camadas desfavorecidas ou afetadas pela guerra civil e calamidades naturais, daí que as vezes o crédito confundia-se com doações, por isso os níveis de reembolso eram 
extremamente baixos. Cassamo (2008), acrescenta que constitui ainda constrangimento o fato de haver muita independência em relação as ONGs que providenciam os serviços de microcrédito e alvo eram os beneficiários e não clientes o que por vezes criava situações de pouca transparência em relação as modalidades de concessão dos créditos.

II. Fase de 1998 até 2000: a economia começa a perceber os mecanismos e a importância do microcrédito como negócio, por conseguinte verifica-se uma redução significativa de casos de créditos não reembolsados devido, por um lado a melhoria de mecanismos de concessão, gestão e monitoria por parte das Instituições de Microfinanças (IMFs) e, por outro a conscielização do cidadão emprestador da necessidade de reembolso obrigatório do microcrédito, contrariamente a fase anterior em que este considerava o microcrédito como um donativo.

III. Fase de 2001 até 2004- Ciente da necessidade de regulamentação da atividade microfinanceira, para alcance da política de redução da pobreza, o estado moçambicano começa a ver as IMFs como parceiras estratégicas fortificando-se ainda mais a base do microcrédito comercial que começaram na fase anterior. As IMFs identificam claramente o seu grupo alvo e procuram-se tornar em instituições maximizadoras de retornos não só por meio de diversificação dos seus produtos como ainda pela expansão geográfica.

A dinâmica do crescimento da economia levou consigo muitos desafios não só a atividade das IMFs como ainda do órgão regulador destas. A nível nacional, para responder ao desafio que o Banco de Moçambique (Banco Central), por meio do decreto 57/2004 de 10 de fevereiro, aprovou o regulamento das Microfinanças (RMF), um documento que continha os termos de referências de cumprimento obrigatório pelas IMFs de acordo com a sua tipologia.

\section{A RELAÇÃO ENTRE MICROCRÉDITO, POBREZA E EMPREENDEDORISMO}

Alice (2011) assume que o grau de desenvolvimento de um país pode ser mensurado através de inúmeros indicadores econômicos. Destes inúmeros indicadores, pode-se assegurar que um dinâmico sistema financeiro é certamente potenciador do crescimento econômico, mas para que isso aconteça, deve haver um sistema forte o suficiente, a ponto de atrair poupadores e investidores nacionais ou estrangeiros. É neste sentido que Milton Santos (2008) afirma que o capital é o fator essencial no circuito superior, onde as linhas de crédito são abertas 
Microcrédito e empreendedorismo: uma análise da situação dos beneficiários do microcrédito da cidade de Xai-Xai, Gaza e Moçambique

seletivamente para estimular a produção. Por sua vez o trabalho é o fator essencial no circuito inferior e são as necessidades de consumo que está na origem do crédito. $\mathrm{O}$ crédito, os intermediários financeiros e o dinheiro líquido são os elementos essenciais para o funcionamento do circuito inferior, sendo que o lucro é menos importante que a sobrevivência.

Schumpeter (1988) relaciona o processo de desenvolvimento econômico às mudanças descontinuas na produção de bens e serviços onde segundo o autor, para haver desenvolvimento, é necessário existir inovação; para existir inovação, deve haver empresário e, finalmente, para que haja empresário, é necessário existir crédito. A partir dessa lógica, aparece a figura do empreendedor, como sendo o indivíduo com capacidade inovadora e produtiva, tornando-se no agente fundamental no processo de crescimento e desenvolvimento econômico.

O objetivo está em prestar assistência financeira à parcela da população que compõe a base da pirâmide social, que não dispõe de patrimônio e/ou rendimento suficiente para apresentar garantias reais nas operações financeiras convencionais. Esses empreendedores são, na maioria das vezes, excluídos do acesso ao crédito concedido pelas instituições financeiras tradicionais, que compõem o SFN (BARONE et al., 2002).

A natureza social de determinado investimento está na sua capacidade de integrar as necessidades básicas de um indivíduo, capaz de causar impactos na qualidade de vida à população pobre, de modo a não só garantir renda, mas também, de prepará-los à realidade das economias globalizadas e competitivas. Dessa forma, deve ser reforçada a concepção de política social, como conjunto de programas e ações contínuas no tempo, que afetam concomitantemente vários fatores das condições básicas de vida da população pobre e é retratada pela exclusão social (SANTOS, 2007, p.57).

Para CARDOSO et al.(2002). o microcrédito é um instrumento de promoção social e geração da cidadania, que não combina com uma política assistencialista. Isso, porque o assistencialismo apenas contribuiria para sustentação e não superação da posição socioeconômica, na qual determinado grupo se encontra.

Nesse contexto, em áreas onde há concentração de pobres, a melhoria econômica e social depende de um conjunto de investimentos, que não se limitam à educação, saúde, alimentação e outros programas emergenciais. O dinamismo econômico que leva a aumentar a geração de empregos e ampliar a estrutura atual do mercado de trabalho, depende da melhora da infraestrutura urbana, para que possibilite atrair e reter capitais. 


\section{APRESENTAÇÃO, ANÁLISE E DISCUSSÃO DOS RESULTADOS}

\section{Perfil dos sujeitos da pesquisa}

O universo pesquisado foi baseado em catorze (14) os beneficiários de microcrédito inqueridos, dos quais $64 \%$ são do sexo feminino e $36 \%$ do sexo masculino. Esse dado mostra a existência de uma maior demanda pelos serviços microfinanceiros por parte das mulheres. Deve-se ainda realçar que atualmente tem se observado um maior número de mulheres desempregadas, razão pela qual buscam pelo microcrédito de modo a se financiarem na perspectiva de gerar algum rendimento. Estes resultados entram em concordância com o modelo proposto por Yuns (2002) na qual afirma que as mulheres têm maior preocupação com as suas obrigações de empréstimos para com a instituição, o que implica numa alta taxa de afluência em relação ao homem, ela se preocupa com o bem estar da sua família, privilegiando assistência à saúde e educação para os filhos.

Quanto a idade dos inqueridos, os dados mostram que $35,7 \%$ possuem idades compreendidas entre os 26 a 30 anos (tabela 1). Esses dados podem ajudar a explicar o porquê que geralmente os indivíduos dessa faixa etária possuem uma maior responsabilidade no seio das suas famílias.

\section{Tabela 1: Faixa Etária dos Inqueridos}

\begin{tabular}{ccc}
\hline Faixa etária & Inqueridos & Percentagem \\
\hline 6 a 18 anos & 0 & $0 \%$ \\
19 a 25 anos & 3 & $21,40 \%$ \\
26 a 35 anos & 5 & $35,70 \%$ \\
36 a 45 anos & 3 & $21,40 \%$ \\
46 a 55 anos & 2 & $14,20 \%$ \\
Mais de 55 anos & 1 & $7,30 \%$ \\
\hline \multicolumn{2}{c}{ Fonte: elaborado pelos autores, $(2019)$}
\end{tabular}

As faixas etárias compreendidas entre os 19 a 25 e 36 a 45 anos, ambas com três inqueridos, o correspondente a 21,4\% ocupam a posição seguinte. Com os dados da tabela acima, observa-se que o número de indivíduos que buscam pelo microcrédito começa a reduzir com o avanço da idade, isso mostra que, quanto maior for a idade do indivíduo menor é a busca pelo financiamento.

No que concerne ao nível de escolaridade dos beneficiários inqueridos, $71 \%$ possuem o nível primário e básico de ensino. Estes dados mostram que o acesso aos serviços de microcrédito está concentrando o seu campo de atuação em populações com um nível académico baixo. Geralmente as pessoas de baixa renda, são as que têm um nível de 
Microcrédito e empreendedorismo: uma análise da situação dos beneficiários do microcrédito da cidade de Xai-Xai, Gaza e

Moçambique

escolaridade baixa e na sua maioria são do sexo feminino, passando por várias necessidades. E como forma de minimizar o sofrimento que passam, recorrem as instituições de microcrédito de modo a obterem algum financiamento e começar com alguma atividade empreendedora e consequente melhora no seu bem estar.

O estudo revelou ainda que $71,4 \%$ dos beneficiários inqueridos são solteiros, $21,4 \%$ são viúvas e apenas 7,3\% dos inqueridos são casados. A presença massiva das solteiras como beneficiárias do microcrédito, mostra que elas são as mais necessitadas, são elas que passam por grandes dificuldades em ter um emprego, são elas que têm tido pouco apoio do companheiro, e solução é a obtenção do microcrédito como um meio de sobrevivência.

Por fim, no concernente ao agregado familiar dos beneficiários de microcrédito, todos eles afirmaram que possuem um agregado familiar relativamente numeroso que varia entre 3 a 8 pessoas em média.

\section{O acesso aos serviços de microcrédito na cidade de Xai-Xai}

O nível de acesso aos serviços de microcrédito na cidade de Xai-Xai é considerado satisfatório. É neste sentido que 64,3\% dos inqueridos afirmaram que não tem tido dificuldades no acesso ao microcrédito, $28,5 \%$ disseram que as dificuldades encontradas para o acesso ao microcrédito são elevadas e 7,2\% dos afirmaram que têm tido poucas dificuldades no acesso aos serviços de microcrédito. Os principais constrangimentos apontados pelos inqueridos tem a ver com o pouco esclarecimento sobre as taxas de juros e dos requisitos para a concessão do microcrédito.

Esses resultados mostram o grau de facilidade que a minoria dos inqueridos encontram na procura dos serviços de microcrédito, já o mesmo não aconteceria se os mesmos procurassem os bancos comerciais (os ditos tradicionais), onde as dificuldades para obtenção do financiamento são muito mais elevadas. Portanto os serviços de microcrédito diferenciam-se dos bancos comerciais tradicionais. A diferença está precisamente no perfil dos clientes ou beneficiários dos serviços financeiros: pequenas empresas, microempresas e famílias pobres. Circuito inferior.

Quando questionados os inquiridos o porquê não recorre aos bancos comerciais para obtenção de empréstimos e consequentemente desenvolver as suas atividades empreendedoras, as principais razões evocadas foram: o fato de muitos deles não serem funcionários públicos e não tem como apresentar o extrato bancário que é um dos principais requisitos para poder ter 
empréstimo, as taxas de juro elevadas e muita burocracia, o que acaba por constranger aos interessados na obtenção dos empréstimos.

As razões evocadas pelos inqueridos pela não opção pelos bancos tradicionais ou comerciais vão ao encontro das Hulme e Arun (2009), que afirmam que a atividade microfinanceira desenvolveu-se para tornar os serviços financeiros acessíveis às populações que não têm acesso às instituições financeiras clássicas. São, portanto, os serviços de poupança e de crédito que são oferecidos às populações cujo rendimento se situa geralmente abaixo da média.

Laice (2000) que afirma que a maioria dos programas de microfinanças teve como embrião projetos de ajuda à população vulnerável, vítima do conflito armado ou de calamidades naturais em que a concessão de créditos "surgiu para garantir um mínimo de recursos para os beneficiários dos seus programas. É importa salientar que a área em estudo tem ciclicamente sofrido com os fenômenos ou desastres naturais, principalmente das cheias que têm destruído o tecido social da região fazendo com que haja muitas populações na situação de vulnerabilidade.

É graças a relativa facilidades que essa população desfavorecida encontra nas instituições de microcréditos existentes na cidade de Xai-Xai (principalmente a SOCREMO e FDM) procuram o financiamento para desenvolverem algumas atividades empreendedoras. É neste sentido, todos os inqueridos procuraram estas instituições e se beneficiaram de empréstimos para desenvolverem as suas atividades. Destes, 36\% afirmaram que receberam montantes que variam entre 20.000 a 50.000 mil meticais (figura 1).

\section{Gráfico 1: Montante de crédito concedidos aos inquiridos.}

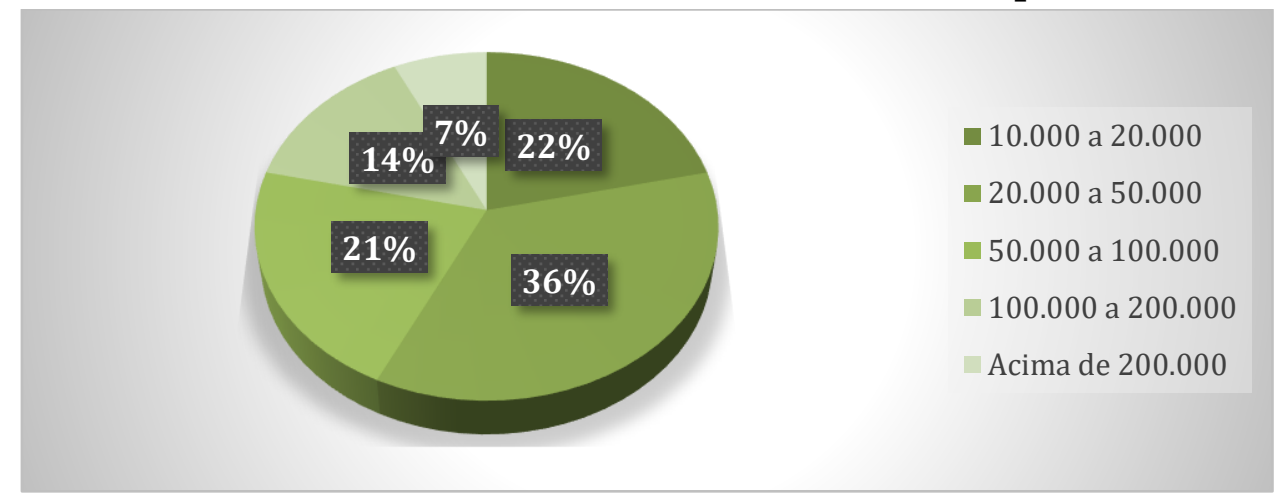

Fonte: elaborado pelos autores, (2019).

Ainda segundo o gráfico acima, 22\% dos inquiridos disseram que foram concedidos pelas instituições de microcrédito montantes que variam entre os 10.000 a 20.000 meticais, $21 \%$ tiveram montantes variando entre os 50.000 a 100.000 mil meticais, $14 \%$ dos inqueridos foram 
Microcrédito e empreendedorismo: uma análise da situação dos beneficiários do microcrédito da cidade de Xai-Xai, Gaza e Moçambique

concedidos montantes que variam entre os 100.000 a 200.000 mil meticais e por fim, $7 \%$ dos inqueridos afirmaram que lhes foi concedido um montante acima de 200.000 mil meticais.

Esses montantes que as várias instituições de microcrédito sediadas na cidade de XaiXai oferecem aos seus clientes, segundo os dados acima estão dentro dos parâmetros afirmado pelo gestor de crédito da SOCREMO quando informou que concede créditos no valor mínimo de 3.000,00 (Três Mil maticais) e máximo até 10.000.000,00 (Dez Milhões de maticais), com as taxas de juros que partem de $3,37 \%$ a $6,25 \%$ dependendo do montante concedido bem como do período acordado entre o devedor e o credor.

Quando indagados os inqueridos se os montantes recebidos eram suficientes para o desenvolvimento das suas atividades que os levou a solicitarem o financiamento, $78,5 \%$ dos inqueridos responderam que o montante concedido foi suficiente justificando que o mesmo valor cobriu os custos que estavam previsto para iniciar com o negócio pretendido, e 21,5\% dos inqueridos afirmaram que o montante recebido não foi suficiente, a razão alegada foi o altos custos de aquisição de material bem como o fundo de maneio necessário para o negócio criado ser muito reduzido, razão pela qual tiveram que buscar ajuda nos familiares e amigos para se financiar.

Em relação aos motivos pelos quais os beneficiados inqueridos, recorrem ao microcrédito, 71,4\% (tabela 2) dos inqueridos afirmaram que recorreram aos serviços de microcrédito devido à falta de emprego, e que sem o emprego não tem como ter algum capital para dar início a uma atividade empreendedora.

Tabela 2 : Razoes evocadas para a procura do microcrédito

\begin{tabular}{lcc}
\hline Motivos da Procura de Microcrédito & Inquiridos & Percentagem \\
\hline Desemprego & 10 & 71,4 \\
Fonte de rendimento & 3 & 21,4 \\
Aumento de rendimento & 1 & 7,2 \\
Outros & 0 & 0 \\
Total & 14 & 100 \\
\hline \multicolumn{3}{c}{ Fonte: elaborado pelos autores, (2019). }
\end{tabular}

Ainda segundo a tabela acima, 21,4\% dos inqueridos buscam o microcrédito como fonte de rendimento e por sua vez, 7,2\% dos inqueridos afirmaram que buscam o microcrédito para aumentarem os seus rendimentos visto que os mesmo já exercem alguma atividade remunerada. Portanto fica claro, tendo em conta esses resultados ou dados, que a procura dos 
serviços de microcrédito para acesso a um financiamento deve-se principalmente a falta de emprego e a busca de fonte de rendimento.

\section{Tipos de empreendimentos criados pelos beneficiários}

Conforme o foi dito anteriormente pelos inquiridos da pesquisa, muitos deles procuraram os serviços de microcrédito como forma de garantir o seu próprio trabalho e criar mais postos de trabalhos para a comunidade onde estão inseridos. E uma das formas de materializar esta pretensão é investir o valor concedido pelas instituições de microcrédito na criação de empreendimentos com vista a desenvolver atividades empreendedoras que depois tornam-se geradoras de emprego.

Quando questionados aos inqueridos sobre os tipos de empreendimentos criados depois do recebimento do microcrédito, todos os inqueridos, afirmaram que apostaram em atividades comerciais para o desenvolvimento das suas atividades. Portanto, fica claro que com a atribuição do microcrédito, os beneficiários passam a apostar no setor de comércio, contribuindo desta maneira para geração do autoemprego e melhoria do bem-estar social. No entanto, esses empreendimentos são fatores que impulsionam o desenvolvimento local, contribuindo assim para a criação de mais postos de trabalho, fornecimento de produtos e na dinamização das atividades econômicas.

Assim sendo, as principais atividades desenvolvidas que foi que foi opção de muitos dos inquiridos com o recebimento do microcrédito, foi criação de pequenos negócios, com $85,70 \%$ (figura 2).

\section{Gráfico 2: Tipos de atividades desenvolvidas pelos beneficiários do microcrédito.}

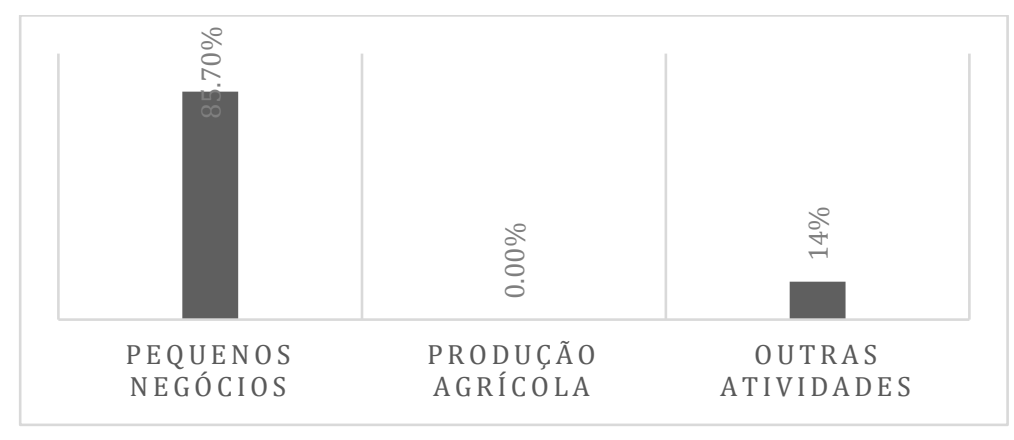

Fonte: elaborado pelos autores, (2019).

A escolha da área dos pequenos negócios, explica-se pelo facto de esta área ser mais ampla, oferecendo assim mais oportunidades de negócio, como por exemplo lojas de venda de produtos alimentares, de higiene, roupa, calçados, entre tantas outras opções. 
Microcrédito e empreendedorismo: uma análise da situação dos beneficiários do microcrédito da cidade de Xai-Xai, Gaza e Moçambique

Com a criação dos seus respectivos empreendimentos, 85,7\% dos inqueridos afirmaram que a sua situação econômica melhorou e 14,3\% dizem que a criação dos seus empreendimentos possibilitou ter mais rentabilidade socioeconômica. Esses resultados dão razão a Fumo (2015) quando afirma que existe três fatores pelos quais a pobreza e as microfinanças se interceptam que são: o alcance aos pobres; a criação de instituições e a ampliação do alcance do sistema financeiro. A capacidade das microfinanças em lidar com esses três fatores constitui uma importante estratégia para o alívio da pobreza.

Assim sendo, as instituições de microfinanças facilitam o acesso ao capital produtivo que conjuntamente com o capital humano e social permitem a redução da pobreza. Assim os pobres (atendendo que são o grupo alvo das microfinanças) poderão promover o autoemprego ou autotrabalho, criar capital produtivo e correta gestão do capital detido, garantido desse modo a satisfação das necessidades básicas para seus agregados familiares, fato esse que está ocorrendo com beneficiários de microcrédito inquiridos no presente estudo.

Em relação a natureza jurídica dos empreendimentos criados, o resultado da pesquisa revela que $92,7 \%$ representa uma atividade empreendedora unipessoal e 7,3\% são empreendimentos familiares (característica do circuito inferior). Relativamente a sustentabilidade do empreendimento, 92,8\% responderam que o seu negócio é sustentável na medida em que o mesmo gera lucro, cobre boa parte das despesas e serve para ajudar com as despesas de casa, como alimentação, educação etc, e finalmente 7,2\% dos inqueridos alegam que o negócio não chega a ser tão sustentável visto que as receitas não cobrem os custos incorridos no negócio, devido a fatores ligados a pouca procura dos produtos comercializados nos seus estabelecimentos comercias bem como a concorrência no mercado onde operam.

\section{Benefícios trazidos pela concessão do microcrédito aos beneficiários}

Quanto ao contributo que o microcrédito trouxe aos beneficiários, $71.3 \%$ dos inqueridos afirmaram que obtiveram melhorias nas suas condições financeiras (tabela 3).

Tabela 3: Contributo da concessão do microcrédito na vida dos beneficiários

\begin{tabular}{lcc}
\hline Contributo do Microcrédito & Inquiridos & Percentagem \\
\hline Melhorar as condições financeiras & 10 & $71.3 \%$ \\
Sustentabilidade do negócio & 3 & $21.4 \%$ \\
Outro & 1 & $7.3 \%$ \\
Total & 14 & $100 \%$ \\
\hline
\end{tabular}

Fonte: elaborado pelos autores, (2019). 
Ainda com base nos dados da tabela acima, 21,4\% dos inqueridos afirmaram que com a concessão do microcrédito obtiveram mais sustentabilidade no negócio, e 7,3\% alcançaram outros impactos positivos como resultado do recebimento do microcrédito no fomento de atividades empreendedoras.

No que tange aos impactos econômico e financeiro dos empreendimentos no mercado formal, os dados da pesquisa, mostram que 64,2\% dos inqueridos afirmaram que o impacto econômico e financeiro no mercado formal é médio, enquanto que $28,5 \%$ afirmaram que os impactos são elevados e por último, 7,3\% afirmaram que os impactos econômicos e financeiros são muito elevados.

\section{CONSIDERAÇÕES FINAIS}

A criação dos serviços de microcrédito foi principalmente pensada para população de baixa renda, geralmente excluída do sistema financeiro formal. Logo, pode-se considerar que esses serviços são impulsionadores do combate à pobreza e de inclusão sócio financeira e como meio de promoção do gênero (a camada feminina).

A pesquisa teve como objeto de estudo beneficiários de microcrédito fornecidas por duas instituições de microcrédito que atuam na cidade de Xai-Xai, província de Gaza nomeadamente a SOCREMO e FDM. Os dados obtidos pela pesquisa confirmam que as mulheres são as principais beneficiárias desses serviços, uma vez que são as mais vulneráveis e a maioria são chefes de famílias e não possuem nenhuma fonte de renda. Trata-se de indivíduos com baixo nível de escolaridade e sem emprego em Moçambique, razão mais que suficiente para o surgimento das instituições de microfinanças para dar apoio a essa classe social de baixa renda sem garantias, tornando deste modo, o microcrédito uma ferramenta alternativa de trabalho e fonte de rendimento.

A pesquisa constatou que a maioria dos que se beneficiaram do microcrédito e consequentemente passaram a desenvolver atividades empreendedoras, reconhecem a importância do microcrédito no desenvolvimento socioeconômico da cidade de Xai-Xai, pois, segundo eles, através do microcrédito, conseguiram criar uma nova classe empresarial que contribuiu na obtenção de renda e consequentemente na melhora do bem-estar social.

Foi possível ainda constatar que existe uma grande procura dos serviços de microcrédito como forma de acessar ao crédito que é considerado por muitos do grupo social de baixa renda, serviços menos burocráticos e com taxas de juros bastante acessíveis. 
Microcrédito e empreendedorismo: uma análise da situação dos beneficiários do microcrédito da cidade de Xai-Xai, Gaza e

Assim sendo, os resultados da presente pesquisa mostram e provam que as instituições de microcrédito contribuem no fomento de atividades empreendedora e no desenvolvimento socioeconômico.

\section{REFERÊNCIAS}

ALICE, L.; RUPPENTHAL, J. E. Microcrédito como fomento ao empreendedorismo na base da pirâmide social. GEPROS. Gestão da Produção, Operações e Sistemas, Ano 7, nº 1, p. 23-34 jan-mar/2012.

ALVES, S. D. S. SOARES, M. M. Democratização do crédito no Brasil - atuação do Banco Central. Brasília: Bacen, 2004.

BARONE, F. M.; et.al. Introdução ao microcrédito. Brasília: Conselho da Comunidade Solidário, 2002.

CARDOSO, R.; et.al. Comunidade Solidária: fortalecendo a sociedade, promovendo o desenvolvimento. Rio de Janeiro: Comunistas, 2002.

COSTANZI, Rogério Nagamine. Microcrédito no âmbito das políticas públicas de trabalho e renda. Revista Mercado de Trabalho - Conjuntura e Análise, ano 7, p. 21-25, jun. 2002.

FERNANDES, M. Micro-crédito em Cabo Verde Papel do Microcrédito no Combate a Pobreza Em Santa Catarina. Cabo Verde: Universidade Jean Piaget, 2008.

FUMO, Sérgio Domingos. Acesso aos Serviços Financeiros para as Familias Rurais em Moçambique: estudo de Caso de Poupança e Crédito Rotativo nas Províncias de Nampula e Sofala. Maputo: FAEF-UEM, 2015.

GIL, A. C. Métodos e técnicas de pesquisa social. 5. ed. São Paulo: Atlas, 1999.

HULME, D. e MOSLEY, P. Finance Against Poverty. Routledge, 1996.

LAICE, A. Evolução das Microfinanças em Moçambique: Ênfase no Microcrédito e na Gestão Financeira. Maputo: FE - UEM, 2000. 
LHACER, Priscilla Maria Vila. Acesso ao Crédito pela População de Baixa Renda: a Experiência do Microcrédito e o Mecanismo de Aval Solidário. Dissertação de Mestrado. Universidade de São Paulo - Faculdade de Economia, Administração e Contabilidade. São Paulo, 2003.

NITSH, M. \& SANTOS,C. A Da repressão financeira ao microcrédito. Revista de Económica Política. São Paulo, Vol.21,nº (84), p. 172-183, 2001.

PARENTE, Silvana. Microfinanças: Saiba o que é um banco do povo. Agência de educação para o desenvolvimento. Brasilia: BNDES, 2002.

SANTOS, Milton. O espaço dividido: os dois circuitos da economia urbana. $2^{\text {a }}$ ed. São Paulo: Editora da Universidade de São Paulo, 2008.

SANTOS, C. A. Análise de impactos socioeconômicos do microcrédito: dificuldades metodológicas e analíticas. Rev. Adm. Pública, Rio de Janeiro, v. 41, nº 1, 2007.

SILVA, M. R. O papel do microcrédito e das microfinanças como Instrumentos de redução da pobreza. VII Congresso Internacional Del Clad Sobre La Reforma Del Estado Y De La Administración Pública, Lisboa, Portugal, 8-11 Oct. 2002.

SCHUMPETER, J. A. A teoria do desenvolvimento econômico. $3^{\text {a }}$ ed. São Paulo: Nova Cultura, 1988.

YUNUS, M.; JOLIS, A. O banqueiro dos pobres: a revolução do microcrédito que ajudou os pobres. $1^{\mathrm{a}}$ ed. São Paulo: Ática, 2000.

Recebido em Julho de 2020

Aprovado em Julho de 2020

Publicado em Fevereiro de 2021 